\title{
Revealing the unexplored fungal communities in deep groundwater of crystalline bedrock fracture zones in Olkiluoto, Finland
}

\author{
Elina Sohlberg *, Malin Bomberg, Hanna Miettinen, Mari Nyyssönen, Heikki Salavirta, \\ Minna Vikman and Merja Itävaara
}

VTT Technical Research Centre of Finland, Espoo, Finland

OPEN ACCESS

Edited by:

Paul Bodelier,

Netherlands Institute of

Ecology (NIOO-KNAW), Netherlands

Reviewed by:

William D. Orsi,

Woods Hole Oceanographic

Institution, USA

Vanessa Rédou,

Université de Bretagne Occidentale,

France

*Correspondence:

Elina Sohlberg,

VTT Technical Research Centre of

Finland, Tietotie 2, Espoo 02150,

Finland

elina.sohlberg@vtt.fi

Specialty section

This article was submitted to

Terrestrial Microbiology,

a section of the journal

Frontiers in Microbiology

Received: 17 April 2015

Accepted: 25 May 2015

Published: 09 June 2015

Citation:

Sohlberg E, Bomberg M, Miettinen H,

Nyyssönen M, Salavirta H, Vikman M

and Itävaara M (2015) Revealing the unexplored fungal communities in

deep groundwater of crystalline bedrock fracture zones in Olkiluoto

Finland. Front. Microbiol. 6:573.

doi: $10.3389 /$ fmicb.2015.00573
The diversity and functional role of fungi, one of the ecologically most important groups of eukaryotic microorganisms, remains largely unknown in deep biosphere environments. In this study we investigated fungal communities in packer-isolated bedrock fractures in Olkiluoto, Finland at depths ranging from 296 to $798 \mathrm{~m}$ below surface level. DNA- and cDNA-based high-throughput amplicon sequencing analysis of the fungal internal transcribed spacer (ITS) gene markers was used to examine the total fungal diversity and to identify the active members in deep fracture zones at different depths. Results showed that fungi were present in fracture zones at all depths and fungal diversity was higher than expected. Most of the observed fungal sequences belonged to the phylum Ascomycota. Phyla Basidiomycota and Chytridiomycota were only represented as a minor part of the fungal community. Dominating fungal classes in the deep bedrock aquifers were Sordariomycetes, Eurotiomycetes, and Dothideomycetes from the Ascomycota phylum and classes Microbotryomycetes and Tremellomycetes from the Basidiomycota phylum, which are the most frequently detected fungal taxa reported also from deep sea environments. In addition some fungal sequences represented potentially novel fungal species. Active fungi were detected in most of the fracture zones, which proves that fungi are able to maintain cellular activity in these oligotrophic conditions. Possible roles of fungi and their origin in deep bedrock groundwater can only be speculated in the light of current knowledge but some species may be specifically adapted to deep subsurface environment and may play important roles in the utilization and recycling of nutrients and thus sustaining the deep subsurface microbial community.

Keywords: fungal communities, high-throughput sequencing, crystalline bedrock fracture, Fennoscandian shield, deep biosphere

\section{Introduction}

Fungi are mainly decomposers that play a major role in the biodegradation of plant materials in terrestrial ecosystems. In deep biosphere environments, however, fungal diversity, and their role in ecosystem functioning remains largely unknown. According to the small number of studies conducted thus far viable fungi have been detected in different sub-seafloor and subterranean environments, such as groundwater aquifers, continental sedimentary and hard rocks, and deep 
subseafloor sediments (Sinclair and Ghiorse, 1989; Madsen and Ghiorse, 1993; Fredrickson and Onstott, 1996; Palumbo et al., 1996; Raghukumar and Raghukumar, 1998; Ludvigsen et al., 1999). Based on a recent review by Nagano and Nagahama (2012) deep sea extreme environments harbor diverse fungal communities. These fungi represent mainly Ascomycota phyla with Eurotiomycetes, Dothideomycetes, Sordariomycetes, and Saccharomycetes being the most abundant fungal classes but also fungi belonging to Basidiomycota and Chytridiomycota have been detected with culture-independed methods. The first viable fungi isolated from deep continental hard rock environments originated from deep crystalline bedrock aquifers in Äspö, Sweden (Pedersen, 1987) and later several yeast species were detected also with DNA-based methods (Pedersen et al., 1996).

Physiological properties of fungi isolated with traditional cultivation-based methods from deep crystalline bedrock fractures indicate that they are adapted to and capable of growing in the subterranean environment (Ekendahl et al., 2003). Identification of facultative anaerobic or strictly anaerobic fungi from deep sea environments indicates that anaerobic conditions are not a limiting factor for fungal growth (Cathrine and Raghukumar, 2009; Jebaraj et al., 2010; Raghukumar, 2012). Remains of bacterial biofilms in these environments also suggest that the biofilms may have supported the nutritious demands of the fungal cells in otherwise extremely oligotrophic environments (Gadd, 2006). Fungi generally prefer mono- or polysaccharides as carbon and energy sources, which would have been provided by the bacterial biofilms. In addition, fungi may be involved in the formation of humic aggregates and carbon contribution by fungal biomass as well as production of extracellular enzymes involved in the cycling of nutrients, as suggested by Raghukumar et al. (2010).

Cultivation-based techniques reveal only a small part of the fungal communities in any environment and with these methods activity of fungi in deep subsurface environments cannot be determined. Novel sequencing technologies would have great potential for obtaining new information on the diversity and ecological role of fungi in the deep geosphere. However, in contrast to the characterization of the bacterial and archaeal communities of deep subsurface habitats, the fungal communities in deep crystalline bedrock fractures have not been characterized by modern culture-independent methods, such as high throughput amplicon sequencing. In this study DNA- and cDNA-based high-throughput amplicon sequencing analysis of the fungal internal transcribed spacer (ITS) gene markers was used to examine the total fungal diversity and to identify the active members of the fungal communities in deep bedrock fracture zones at different depths in Olkiluoto, Finland. The results reveal previously unexplored fungal communities in deep groundwater of crystalline rock fracture zones.

\section{Materials and Methods}

\section{Site Description and Sampling}

Olkiluoto is an island situated in the western coast of Finland. The bedrock of Olkiluoto belongs to the Fennoscandian Shield and consists mostly of Precambrian highly deformed and metamorphosed migmatitic mica gneisses. The characteristics of the site have been described in more detail by Pitkänen et al. (2004), Posiva (2013), Nyyssönen et al. (2012) and Bomberg et al. (2015). In brief, the groundwater in Olkiluoto is anaerobic and saline and salinity increases with depth from $0.1 \mathrm{~g} \mathrm{~L}^{-1}$ at ground level to $100 \mathrm{~g} \mathrm{~L}^{-1}$ at $900 \mathrm{~m}$. The temperature of the groundwater varies from ca. $7^{\circ} \mathrm{C}$ at $50 \mathrm{~m}$ to $20^{\circ} \mathrm{C}$ at $1000 \mathrm{~m}$ and $\mathrm{pH}$ is slightly alkaline in all fracture zones. Sulfate is enriched in the upper $300 \mathrm{~m}$ and beneath this depth zone, only traces of sulfate are observed. The concentration of methane increases with depth from $300 \mathrm{~m}$.

Altogether, deep groundwater samples from 17 different boreholes at depths ranging from 296 to $798 \mathrm{~m}$ were collected between December 14th, 2009 and August 21st, 2013 from the Olkiluoto island in Finland (Table 1). Sampling was done as described in Bomberg et al. (2015). In short, the samples were collected from multi-packered boreholes as well as from open boreholes where the sampling section was packered-off in order to seal off a specific water-conducting fracture zone from the rest of the borehole. This isolated fracture zone was purged by pumping out the water collected between the packers and allowing water from the isolated fracture zone to run into the packered off section of the borehole. In order to assure that sample water was coming only from fracture zones, the packersealed fracture zones were pumped for at least 4 weeks before sampling. The conductivity and $\mathrm{pH}$ of the pumped water was followed, and when the values settled, it was assumed that the water represents the endemic fracture zone water. Microbial biomass for nucleic acid analyses was concentrated from 500 to $1000 \mathrm{~mL}$ samples by filtration on cellulose acetate filters $(0.2 \mu \mathrm{m}$ pore size, Corning) by vacuum suction in the anaerobic chamber. The filters were immediately cut out from the filtration funnels with sterile scalpels and frozen on dry ice.

\section{Geochemical Analyses of the Groundwater}

Conductivity, $\mathrm{pH}$, total dissolved solids (TDS), alkalinity, total organic, and dissolved inorganic carbon and different cations and anions were analyzed from the sampled groundwater. Analysis methods are described before (Posiva, 2013; Bomberg et al., 2015). All analyses were conducted by Posiva Oy (Olkiluoto, Finland).

\section{Nucleic Acid Isolation}

Total DNA was isolated directly from the frozen cellulose-acetate filters. The filters were cut to pieces with sterile scalpels in a laminar flow hood, and the DNA was extracted and purified with the PowerSoil DNA extraction kit (MoBio Laboratories, Inc., Solana Beach, CA). The isolation was performed according to the instructions of the manufacturer. The isolated and purified DNA was then stored frozen at $-80^{\circ} \mathrm{C}$ until use. Total RNA was isolated directly from the frozen cellulose-acetate filter with the PowerWater RNA isolation kit (MoBio Laboratories, Inc., Solana Beach, CA). The filters were thawed on ice and care was taken to minimize the time of thawing. The intact filters were inserted into the bead tubes with flame-sterilized forceps and the RNA extraction was performed according to the manufacturer's instructions. Negative DNA and RNA isolation controls were 
TABLE 1 | Selected hydrogeochemical characteristics of the Olkiluoto fracture zones investigated in this study.

\begin{tabular}{|c|c|c|c|c|c|c|c|}
\hline Sample* & $\mathrm{Ec}(\mathrm{ms} / \mathrm{m})$ & $\mathrm{pH}$ & TDS (mg L-1) & $\mathrm{N}$ tot $\left(\mathrm{mg} \mathrm{L}^{-1}\right)$ & NPOC (mgC L-1) & DIC (mgC L-1) & $\mathrm{HCO}_{3}\left(\mathrm{mg} \mathrm{L}^{-1}\right)$ \\
\hline OL-KR13/296m_10 & 897 & 7.9 & 4994 & 0.71 & 10 & 27 & 134 \\
\hline OL-KR13/296m_12 & 807 & 7.8 & 4481 & 4.4 & 38 & 28 & 116 \\
\hline OL-KR3/303m_12 & 987 & 8 & 5378 & 0.6 & 7.8 & 4.3 & 26 \\
\hline OL-KR20/323m_13 & 1116 & 7.7 & 6242 & 0.91 & 11 & 13 & 67 \\
\hline OL-KR6/328m_10 & 1832 & 7.9 & 10670 & $<0.05$ & $<2.40$ & 4.1 & 22.6 \\
\hline OL-KR6/330m_13 & 1800 & 8 & 10590 & 0.051 & $<2.40$ & 4.6 & 27 \\
\hline OL-KR25/330m_11 & 642 & 7.9 & 3502 & 0.96 & 13 & 33 & 171 \\
\hline OL-KR3/340m_11 & 1012 & 8.3 & 5656 & 1.1 & 12 & 4.1 & 25 \\
\hline OL-KR23/347m_09 & 2190 & 7.5 & 12710 & 0.42 & 5.1 & 3.9 & 17.1 \\
\hline OL-KR46/372m_13 & 1778 & 7.7 & 10460 & 1.5 & 18 & 5.9 & 32 \\
\hline OL-KR46/390m_13 & 1701 & 7.7 & 10370 & 0.86 & 4.7 & 18 & 98 \\
\hline OL-KR5/405m_12 & 2170 & 8.1 & 12880 & 1.2 & 19 & $<3$ & 16 \\
\hline OL-KR49/415m_09 & 2670 & 8.1 & 15900 & 0.16 & $<3$ & $<3$ & 9.8 \\
\hline OL-KR9/423m_11 & 2300 & 7.5 & 13430 & 0.38 & 5.1 & 3 & 11.6 \\
\hline OL-KR9/510m_11 & 2960 & 8.1 & 18580 & 0.66 & 6.6 & $<3$ & 7.3 \\
\hline OL-KR2/559m_10 & 4110 & 8.6 & 25500 & 1.1 & 11 & $<3.75$ & 17.7 \\
\hline OL-KR1/572m_10 & 3770 & 7.8 & 23260 & 0.41 & 5 & $<3.75$ & 14 \\
\hline OL-KR44/693m_13 & 5520 & 7.3 & 37410 & 10 & 110 & 6.5 & 30 \\
\hline OL-KR29/798m_10 & 7820 & 7.3 & 53210 & 3.1 & $<12$ & $<12$ & 7.9 \\
\hline
\end{tabular}

*Vertical depth and sampling year are presented in the sample name.

also included. DNA contamination of the RNA extracts was checked by PCR with bacterial $16 \mathrm{~S}$ rRNA gene specific primers 8F (Edwards et al., 1989) and P2 (Muyzer et al., 1993). If no PCR product was obtained, sample was assumed uncontaminated and the RNA extract was submitted to cDNA synthesis. If a PCR product was obtained, the RNA extract was first treated with DNase (Promega, Madison, WI) according to the manufacturer's instructions before cDNA synthesis. Aliquots of $11.5 \mu \mathrm{L}$ of RNA was incubated together with $250 \mathrm{ng}$ random hexamers (Promega, Madison, WI) and $0.83 \mathrm{mM}$ final concentration dNTP (Thermo Fisher Scientific, Vantaa, Finland) at $65^{\circ} \mathrm{C}$ for $5 \mathrm{~min}$ and cooled on ice for $1 \mathrm{~min}$. The cDNA was synthesized with the Superscript III kit (Invitrogen), by adding $4 \mu \mathrm{L} 5 \times$ First strand buffer, 40 U DTT and $200 \mathrm{U}$ Superscript III to the cooled reactions. To protect the RNA template from degradation, $40 \mathrm{U}$ recombinant RNase inhibitor, RNaseOut (Promega, Madison, WI), was used. The reactions were incubated at $25^{\circ} \mathrm{C}$ for $5 \mathrm{~min}$, at $50^{\circ} \mathrm{C}$ for $1 \mathrm{~h}$ and at $70^{\circ} \mathrm{C}$ for $15 \mathrm{~min}$. Two to four parallel reactions per sample as well as no template controls were performed. The parallel reactions were subsequently pooled. RT-PCR was also performed on the negative RNA extraction controls as well as negative reagent RT-PCR controls.

\section{Amplification Library Preparation}

The amplification libraries for 454 high throughput sequencing were prepared by PCR from the DNA and cDNA samples. Fungal ITS fragments were amplified in a two-step PCR. First, a 420825 bp long fragment was amplified with primers ITS1F and ITS4 (White et al., 1990; Gardes and Bruns, 1993). Length of the ITS region varies between species (Manter and Vivanco, 2007). The product of this PCR was used as template in a secondary PCR with tagged primers ITS1F and ITS2 (Buée et al., 2009) generating a ca. $400 \mathrm{bp}$ product. First step of PCR amplification was performed in $10 \mu \mathrm{L}$ and second step in $50 \mu \mathrm{L}$ reactions containing 1x KAPA Fidelity buffer (Kapa Biosystems, Cape Town, South Africa) ( $2 \mathrm{mM} \mathrm{MgCl} 2), 0.3 \mathrm{mM}$ final concentration of dNTP, $6 \mathrm{pmol}$ of each primer in $10 \mu \mathrm{L}$ reaction and $25 \mathrm{pmol}$ in $50 \mu \mathrm{L}$ reaction, 1 unit of KAPA Hifi polyeraze enzyme (Kapa Biosystems, Cape Town, South Africa) and $1 \mu \mathrm{L}$ of template. The PCR program for both PCR steps consisted of an initial denaturation step at $98^{\circ} \mathrm{C}$ for $5 \mathrm{~min}, 39$ cycles of $20 \mathrm{~s}$ at $98^{\circ} \mathrm{C}, 50 \mathrm{~s}$ at $50^{\circ} \mathrm{C}$, and $30 \mathrm{~s}$ at $72^{\circ} \mathrm{C}$. A final elongation step of $5 \mathrm{~min}$ was performed at $72^{\circ} \mathrm{C}$. In addition negative reagent PCR controls with only PCR-grade water as template were performed to rule out possible contamination. PCR products were confirmed in 1 $\times$ SYBR safe-stained $1 \%$ agarose gel electrophoresis. The pyrotag libraries were sent for sequencing to Beckman Coulter Genomics (Danvers, MA, USA) where amplicon libraries were purified and smallest and largest fragments were removed based on fragment analysis. Pyrotaq libraries were run on a Genome Sequencer FLX 454 System according to manufacturer's protocol (454 Life Sciences/Roche Applied Biosystems, Branford, CT, USA).

\section{Sequence Processing and Analysis}

The sequence reads obtained from the 454 high-throughput sequencing were partly processed with in-house pipeline (Salavirta et al., in press). First, sequences were subjected to quality control using the MOTHUR software version v.1.31.2 (Schloss et al., 2009). During this step, adapters, barcodes, and primers were removed from the sequence reads, and the quality of base-calls was assessed in order to remove erroneous reads from the data set. Subsequently, chimeric sequence reads were removed from the data set with the USEARCH algorithm version 5.2.236 (Edgar, 2010) by de novo detection and through similarity 
searches against the $97 \%$ representative OTU set of the UNITE reference database (Kõljalg et al., 2013).

Groups of similar sequences, i.e., Operational Taxonomic Units (OTUs), were selected from the chimera-filtered sequence data set following open-reference OTU-picking protocol of QIIME v. 1.7.0 (Caporaso et al., 2010) against the 97\% identity UNITE database OTU sets (Kõljalg et al., 2013). OTU clustering was performed with UCLUST v. 1.2.22q (Edgar, 2010) and the seed sequences were selected as the representative OTU sequences. Only few fungal sequences were amplified from negative control. This is possibly due to two-step PCR and these OTUs based on these sequences were removed from the entire sequence data set. All reads that failed to hit the UNITE reference database with a minimum of $60 \%$ identity threshold were discarded as sequencing error. Next, singleton OTUs, i.e., OTUs that were represented by a single sequence, were filtered from the data set. Finally, taxonomy from domain to specieslevel was assigned to OTUs via representative OTU sequences with BLASTN with a maximum E-value of 0.001 (Altschul et al., 1990). Alpha diversity indexes chaol (Chao, 1984) and Shannon diversity index (Shannon, 1948) were calculated from normalized sequence data where sequence data was subsampled to 1500 sequences to adjust for sequencing coverage. Heatmaps of the fungal communities were generated in the R environment ( $\mathrm{R}$ Development Core Team, 2008) utilizing the reshape2 (Wickham, 2007), grid (Murrell, 2005), and ggplot2 (Wickham, 2009) packages.

\section{Statistical Analysis}

Non-metric multidimensional scaling analyses (NMDS) for comparing the similarity of the fungal communities at class level between the different samples and the effect of chemical parameters on the microbial communities was performed using the PAleontological STatistics (PAST) program (Hammer et al., 2001). Non-Euclidean Bray-Curtis distance matrix was generated with PAST and correlation coefficient values of the matrix was calculated with 1000 permutations with R. In addition Pearson's correlation between total (DNA fraction) and active (RNA fraction) fungal communities was calculated at genus level with compare_taxa_summaries.py command within QIIME. Venn diagrams of each sample were calculated with MOTHUR showing shared OTUs between DNA and RNA fraction.

\section{Accession Numbers}

The fungal ITS gene region sequences have been submitted to the European Nucleotide Archive (ENA, https://www.ebi.ac.uk/ena/) under accession numbers ERS706390- ERS706426.

\section{Results}

\section{Fungal Diversity and Community Structure in Different Bore Holes}

Fungal sequences were detected in the DNA fraction of all of the 19 analyzed fracture water samples and in 18 samples of the RNA fraction. In total 378,831 quality-filtered fungal ITS sequences were obtained from the different fracture zones. The number of obtained sequences ranged from 306 to 24,616 in different samples with a median of 10,941 sequences per sample (Table S1). When comparing the Chaol OTU richness estimate values to true detected OTU numbers, $22-100 \%$ of estimated fungal OTUs were obtained from the subsampled sequence data meaning that sequencing depth was sufficient enough to fully characterize the fungal communities in most of the samples. Altogether, 965 fungal OTUs ranging from 33 OTUs at $328 \mathrm{~m}$ in OL-KR6 to 163 OTUs in OL-KR9 at $423 \mathrm{~m}$ in DNA fraction and 7 OTUs in OL-KR3 at $303 \mathrm{~m}$ to 69 OTUs at $330 \mathrm{~m}$ and $405 \mathrm{~m}$ in RNA fraction were detected in the total sequence data (Table S1). Fungal diversity based on subsampled OTU richness in the DNA samples originating from the fracture waters peaked at $347 \mathrm{~m}$ in OL-KR23 (79 OTUs) and was lowest at $328 \mathrm{~m}$ in OL-KR6 (19 OTUs) (Figure 1). In RNA fraction highest OTU richness was detected at $390 \mathrm{~m}$ in OL-KR46. However, no clear connection between sampling depth and fungal OTU numbers was detected. In the DNA fraction highest Shannon diversity index $\left(\mathrm{H}^{\prime}=4.3\right)$, which indicates the abundance and evenness of the species present, was obtained at $423 \mathrm{~m}$ depth in sample OLKR9 and lowest at $330 \mathrm{~m}$ depth in sample collected from OL-KR6 $\left(\mathrm{H}^{\prime}=1.0\right)$. In the active fungal community highest diversity was observed at $510 \mathrm{~m}$ in OL-KR9 $\left(\mathrm{H}^{\prime}=3.5\right)$. No fungi were detected in OL-KR44 at $693 \mathrm{~m}$ in the active fungal community.

Most of the observed fungal sequences belonged to the phylum Ascomycota (63.9\%). Phylum Basidiomycota was represented by $8.9 \%$ of all the sequences. Other fungal phyla detected were Chytridiomycota, Glomeromycota, and Zygomycota, which were represented as a minor (0.1-2.1\%) part of the whole fungal community. Altogether approximately $25 \%$ of the fungal sequences obtained were identified as fungal according to UNITE database but a more specific classification remained unknown. This can be due to insufficient representation of fungal sequences in the sequence databases or these species have not been characterized before and could be considered as novel.

Structure of the fungal communities varied between different fracture zones and sampling times (Figure 2). Sequences affiliating with Ascomycota dominated fungal community in both DNA and RNA fraction in most of the fracture zones. However, Basidiomycota was the dominating phylum in OL$\mathrm{KR} 2$ at $559 \mathrm{~m}(58 \%)$ in the total fungal community and in OLKR9 at $423 \mathrm{~m} \mathrm{(98.5 \% )} \mathrm{and} \mathrm{OL-KR29} \mathrm{at} 798 \mathrm{~m}$ in the active fungal communities. In addition, Chytridiomycota was the dominating phylum in OL-KR44 at $693 \mathrm{~m}(66 \%)$ in the total fungal community.

Sordariomycetes from the Ascomycota phylum was the major active fungal class (47-100\% of all the sequences) in most of the boreholes and also the dominating fungal class in the total fungal community in OL-KR13 at $296 \mathrm{~m}$, OL-KR3 at $303 \mathrm{~m}$, OL-KR25 at $330 \mathrm{~m}, \mathrm{OL}-\mathrm{KR} 3$ at $340 \mathrm{~m}, \mathrm{OL}-\mathrm{KR} 49$ at $415 \mathrm{~m}$ and OL-KR29 at $798 \mathrm{~m}$ (39-65\%) (Figure 2). OTUs belonging to Sordariomycetes were mostly related to Nectria genus and minority to Fusarium, Pochonia, Pseudallescheria, and unidentified Hypocreales groups (Figure S1). Fungal class Eurotiomycetes was identified as dominating fungal class in total fungal community of OL-KR20 at $323 \mathrm{~m} \mathrm{(84 \% )}$ and OL-KR6 at 330m (2013) (95\%) and in active fungal community of OL-KR25 at $330 \mathrm{~m}$ (94\%). The majority 

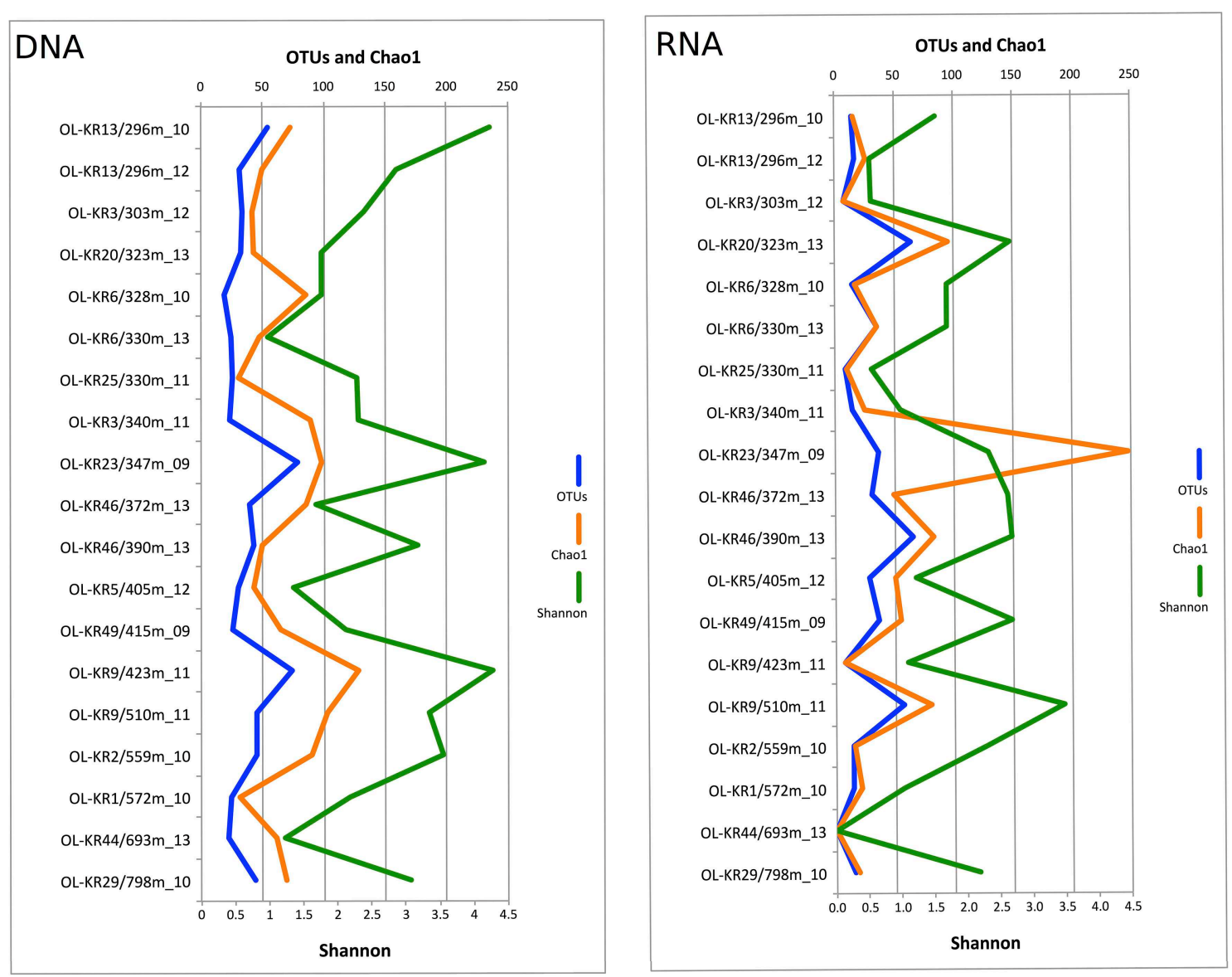

FIGURE 1 | Fungal diversity in deep groundwater of crystalline bedrock fracture zones in Olkiluoto, Finland. Number of observed taxonomic units (OTUs), estimated number of OTUs (Chao1) and Shannon diversity index achieved from the sequence data subsampled to 1500 sequences are presented.

of the sequences belonging to the class Eurotiomycetes were members of the Penicillium genus. In addition sequences most closely related to genus Aspergillus were found from OL-KR46 at $390 \mathrm{~m}$ and OL-KR2 at $559 \mathrm{~m}$ as a minor group. Other detected Ascomycota fungal classes in Olkiluoto groundwater samples were Dothideomycetes that dominated the active community in OL-KR6 at $328 \mathrm{~m}$ (2010) (40,5\%), Leotimycetes that dominated the active fungal community in OL-KR49 at $415 \mathrm{~m} \mathrm{(47 \% )}$ and total identified fungal community in OL-KR6 at $328 \mathrm{~m}(2010)$ (26\%) and OL-KR1 at $572 \mathrm{~m}(23 \%)$ and Saccharomycetes in OLKR25 at $330 \mathrm{~m}(19 \%)$ and OL-KR6 at $328 \mathrm{~m}$ (2010) (5\%) total community (Figure 2). In addition sequences belonging to class Orbilliomycetes was only found in OL-KR13 at $296 \mathrm{~m}$ (2012), but they contributed only as a minor (1.2\%) part of the fungal community.

In OL-KR2 at $559 \mathrm{~m}$ in the total fungal community and OLKR29 at $798 \mathrm{~m}$ in the active community where Basidiomycota was the dominating identified phylum most of the sequences were closely related to class Microbotryomycetes (37-39\%) and more closely to Sporodiobolales order and Sporobolomyces and Rhodotorula genera (Figure S2). In addition in OL-KR2 at $559 \mathrm{~m}$ Tremellomycetes and more specifically Cryptococcus-like yeast sequences were detected in total community and Malasseziales order in active community. Other identified Basidiomycota classes in Olkiluoto boreholes were Agaricomycetes in OLKR13 at $296 \mathrm{~m}$ and in OL-KR49 at $415 \mathrm{~m}$ in the active community (Figure 2). Pucciniomycetes was detected in OLKR46 at $390 \mathrm{~m}$ as a minor part of the total community $(0.2 \%)$. The Chytridiomycota phylum dominated the total fungal community in OL-KR44 at $693 \mathrm{~m}(66 \%)$ and was also present in OL-KR29 at $798 \mathrm{~m}$. Chytridiomycota sequences from these boreholes were most similar with order Rhizophydiales. No Chytridiomycota sequences were detected in the active fungal community.

\section{Statistical Analysis of Fungal Diversity and Correlation to Geochemistry}

Non-metric multidimensional scaling analysis of fungal communities and environmental parameters grouped the samples into four clusters in both DNA and RNA fractures (Figure 3 and Table S2). The deepest samples (693 and $798 \mathrm{~m}$ ) clustered together in the DNA fraction that indicates that depth has an influence in the fungal community structure and fungal communities in the deepest communities are most similar. In addition, at greater depth higher salinity also affect the communities and slightly lower $\mathrm{pH}$ was observed to significantly correlate with fungal community structure $(p<0.05)$. At depths 


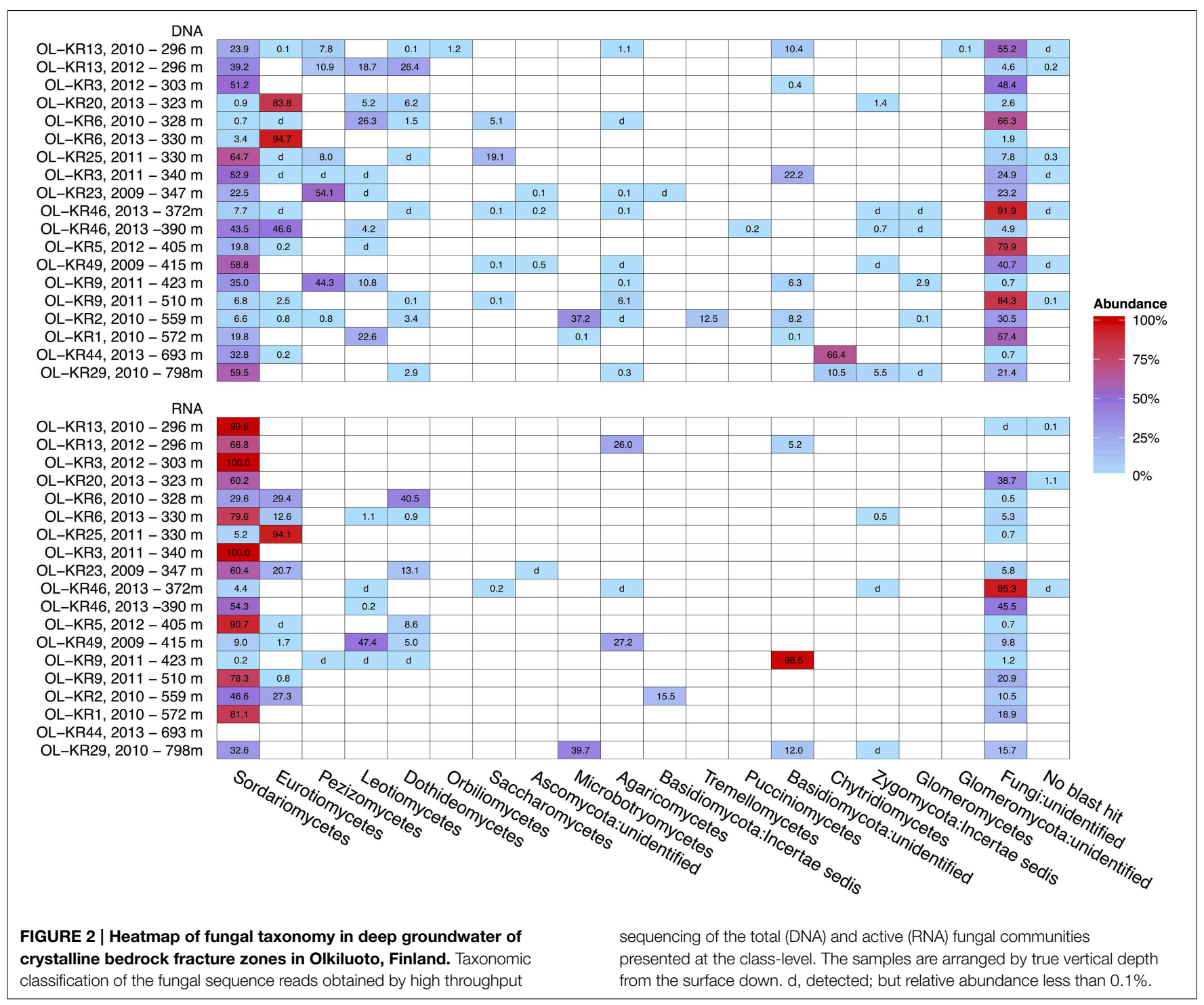

from 296 to $340 \mathrm{~m}$ carbon availability (DIC, $\mathrm{HCO}_{3}$ ) affected the fungal communities in both DNA and RNA fractions and these samples grouped together. In those fracture zones concentrations of DIC and $\mathrm{HCO}_{3}$ were higher than in deeper fracture zones ranging from 4.1 to $33 \mathrm{mgC} \mathrm{L}^{-1}$ of DIC and 25 to $134 \mathrm{mg} \mathrm{L}^{-1}$ of $\mathrm{HCO}_{3}$ (Table 1 and Table S3). Amount of total organic carbon was highest at $693 \mathrm{~m}$ in OL-KR44 where concentration of NPOC was $110 \mathrm{mgC} \mathrm{L}^{-1}$. However, in the NMDS analysis organic carbon concentration did not significantly affect the fungal community structure $(p>0.1)$. Ammonium, nitrate, nitrite, magnesium, and sulfate concentrations were associated with the changes in fungal community profiles especially in OL-KR46 at 372 and $390 \mathrm{~m}$ and OL-KR6 at 328 and $330 \mathrm{~m}$ in both RNA and DNA fraction that grouped together (Figure 3). Especially nitrite and nitrate had a significant effect on the fungal communities in the DNA fraction $(p<0.001)$, but concentrations are very low.

The similarities of fungal communities between DNA and RNA fractions were assessed at genus level by Pearson's one-sided $\mathrm{t}$-distribution tests, with the hypothesis that positive correlation would be detected between total and active communities. In the total dataset Pearson's correlation was $0.33( \pm 0.395 \%$ CI, $p<$ 0.001 ) between the total and active fungal communities. When we compared specific samples, statistically significant correlation $(p<0.05)$ was found in 10 of the 18 fracture zones (Table S4). Statistically significant Pearson's correlations varied between 0.20 and 0.99 with highest correlation found at $372 \mathrm{~m}$ in OL-KR46 and weakest at $303 \mathrm{~m}$ OL-KR3. Moderate or strong correlation was found in seven of the fracture zones $(0.32-0.99)$. The number of shared OTUs between DNA and RNA fraction was $0-23 \%$ (Figure S3).

\section{Discussion}

Terrestrial deep subsurface mycology is still an unexplored research field as the major research done until now has been focusing on the diversity and functional studies of bacteria and archaea. To our knowledge this is the first study where fungal communities in deep groundwater of crystalline bedrock fracture 


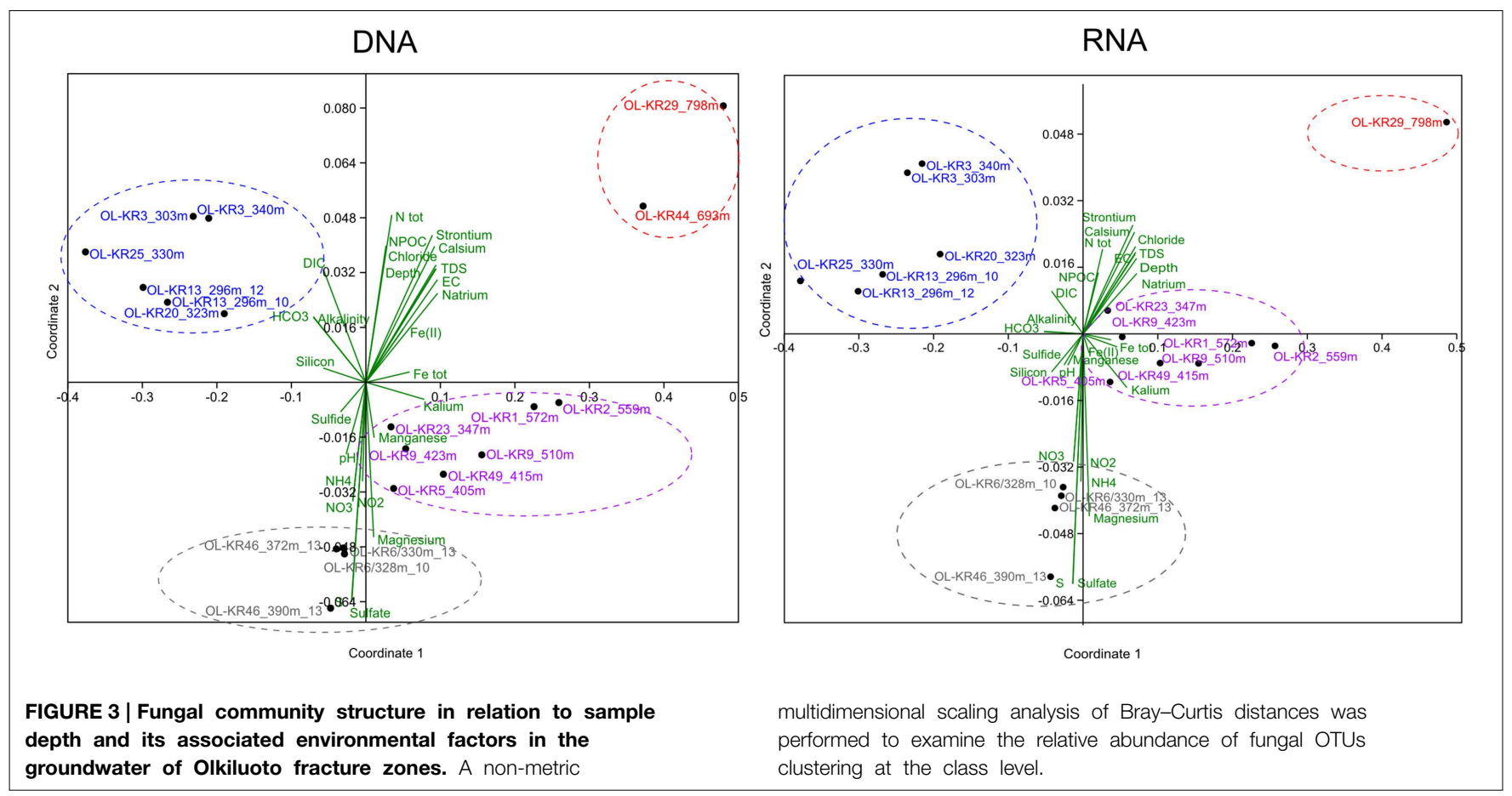

zones were studied using high-throughput amplicon sequencing. Our results show that diverse and active fungal communities exist in the deep subsurface in Olkiluoto, Finland. Actually, in most of the studied fracture zones the fungal diversity was higher than what has been detected so far in deep sea environment. Deep sea studies have reported up to 43 fungal OTUs with $>99 \%$ sequence similarity by using fungal ITS region cloning and sequencing (Lai et al., 2007; Nagano et al., 2010; Singh et al., 2012) and Orsi et al. (2013a) detected up to 26 fungal OTUs with 454 pyrosequencing of the eukaryotic 18S rRNA region, whereas we detected up to 163 OTUs in different fracture zones and depths. In our study fungal ITS1 region was chosen over ribosomal genes because it is highly variable and can separate fungi even at species level (Lindahl et al., 2013). ITS2 is considered generally less variable in length than ITS1 and is somewhat better represented in sequence databases. However, ITS1 and ITS2 share many properties, and similar results can be obtained with these two marker genes (Bazzicalupo et al., 2013). With cultivation-based methods five Rhodotorula and Cryptococcus yeast species and 17 molds have been detected in Fennoscandian rock aquifers in Äspö, Sweden (Ekendahl et al., 2003). Fungi belonging to the Ascomycota phylum were the most abundant in Olkiluoto fracture zones and this is in good agreement with findings from deep sea environments (Nagano and Nagahama, 2012). The deepest fracture zones with higher salinity and temperature and lower $\mathrm{pH}$, were the only ones where fungi belonging to the Chytridiomycota phylum were detected. In addition, the number of basidiomycete species also increased with depth (Figure 2). Altogether 25\% of the fungal sequences remained unidentified and some of these OTUs could be potentially novel species that have not been characterized before.
Fungal diversity in the deep crystalline fracture water in Olkiluoto was surprisingly high. Unexpectedly no fungal OTUs were detected in the RNA fraction at $693 \mathrm{~m}$ depth, where the highest concentration of total organic carbon that fungi could easily use in their metabolism was detected. Although no clear connection between fungal diversity and some of the geochemical parameters were detected, NMDS analysis showed that salinity, which increases with depth, had an influence on the fungal community structure in deeper fracture zones and also nitrogen compounds, sulfate, and inorganic carbon were associated with the changes in the fungal communities at more shallow depths. Fungi are involved in many biogeochemical cycles such as nitrogen and sulfur cycles and fungi are for example able to solubilize minerals, dissolute, and precipitate metal ions, degrade silicates and dissolve rock phosphates in oxygen-limited environments (Gadd, 2006; Sterflinger, 2010). Some filamentous fungi and yeast species are able to oxidase sulfur and sulfur compounds and release sulfate to environment (Wainwright and Grayston, 1989; Reitner et al., 2006; Sterflinger, 2010). Thus, fungi could provide sulfate to sulfate-reducing bacteria and could potentially be involved in the sulfur cycle in subsurface environment. Although fungi and bacteria are competing for the same low amounts of nutrients in subsurface oligotrophic conditions, they can also benefit from each other. For example, Fournier et al. (1998) found that the yeast Rhodotorula rubra has a stimulating effect on the growth of the iron sulfide-oxidizing bacterium Thiobacillus ferrooxidans. Similar cooperation between fungi and bacteria could potentially occur also in Olkiluoto deep fracture zones.

Members of the Sordariomycetes were the most commonly observed fungi from Olkiluoto fracture waters. These fungi are ubiquitous and cosmopolitan and function in virtually all 
ecosystems (Zhang et al., 2006). The group includes pathogens, endophytes of plants, mycoparasites and saprobes involved in decomposition and nutrient cycling but their role in deep biosphere ecosystems is not studied. Sordariomycetes are together with Eurotiomycetes, Saccharomycetes and Dothideomycetes one of the most frequently detected fungal taxa in deep sea environments where living conditions resemble the ones of subterranean deep fracture zones (Nagano and Nagahama, 2012). However, phylotypes within the class Sordariomycetes are few and unique to the studied deep sea areas and their role and functions are still unknown. The fungal sequences obtained from Olkiluoto fracture waters belonging to the Sordariomycetes class were closely related to members of the Nectriaceae family and Nectria and Fusarium genera. The family Nectriceae includes, e.g., facultative anaerobic microscopic fungi capable of using nitrate or nitrite as alternative terminal electron acceptor in their respiration in the absence of oxygen (Kurakov et al., 2008). Fungal species belonging to Nectria have been detected in deep sea sediments (Singh et al., 2012). Some species belonging to genus Fusarium that are capable of denitrification have been found in deep sea environments, especially from oxygen-depleted regions (Jebaraj et al., 2010).

NMDS analysis showed correlation between fungal community in OL-KR6 at $330 \mathrm{~m}$, where the most Penicillium -sequences were detected, and ammonium, nitrate and nitrite concentrations. This indicates that these species might be involved in nitrogen cycle also in the deep fracture zones in Olkiluoto. Strong correlation between fungal diversity and nitrate has been found also from deep marine sediments (Orsi et al., 2013b) Penicillium and Aspergillus species are common in outdoor air and terrestrial environments but they are also frequently detected in deep sea environments (Nagano and Nagahama, 2012; Raghukumar, 2012). Deep sea species differed from terrestrial species by their physiological properties and that they were adapted to an aqueous environment (Raghukumar and Raghukumar, 1998; Damare et al., 2006; Damare and Raghukumar, 2008). Salt-tolerant Penicillium and Aspergillus species have also been identified from oxygen-deficient environments (Raghukumar, 2012) and from anaerobic marine sediments where they were reported to play on important role in the denitrification process (Jebaraj et al., 2010). This suggests a possible versatile role of fungi in major ecological processes in extreme nutrient-poor environments, such as Olkiluoto deep fracture zone fluid. Aureobasidium and Cladosporium genera found especially in OL-KR6 at $328 \mathrm{~m}$ from the RNA-fraction and OL-KR13 at $296 \mathrm{~m}$ from the DNA-fraction are reported in many deep sea environment studies (Damare et al., 2008). Common characteristics of these fungal groups are resistance or adaptation to high osmotic pressure that is essential for survival in extreme conditions such as the ones in deep subsurface environments.

The most common classes of the Basidiomycota phylum detected in Olkiluoto groundwater were Microbotryomycetes, Tremellomycetes, and order Malasseziales. These fungal groups are common in deep sea environments (Nagano and Nagahama, 2012) and RNA transcripts from active species within these phyla have been detected in deep marine sediments (Orsi et al., 2013a). Yeast genera within class Microbotryomycetes detected from Olkiluoto were Rhodotorula and Sporobolomycetes related species. The Rhodotorula strain isolated from Fennoscandian rock aquifers in Äspö was able to grow in a wide range of $\mathrm{NaCl}$ concentrations $\left(0-100 \mathrm{~g} \mathrm{~L}^{-1}\right)$ and $\mathrm{pH}$ interval of 410 at temperatures ranging from 4 to $30^{\circ} \mathrm{C}$ (Ekendahl et al., 2003). Salinity, $\mathrm{pH}$ and temperature in Olkiluoto are also within these limits. This indicates that these yeast species are adapted to conditions in the deep subsurface environment. In Olkiluoto Sporobolomycetes related species were also detected in the RNA-fraction, which proves that these species were active in these conditions. Cryptococcus-like yeasts from class Tremellomycetes that were identified from Olkiluoto have also been detected from other deep igneous rock aquifers sites on the Fennoscandian shield (Ekendahl et al., 2003) and deep sea environments like deep sea methane seeps (Takishita et al., 2006, 2007). Cryptococcus-like yeasts were identified from the active community in OL-KR2 at $559 \mathrm{~m}$ where also high methane concentration ( $386 \mathrm{ml} \mathrm{L}^{-1}$ ) was detected (Bomberg et al., 2012) that fungi could potentially use in their metabolism. Yeast genera within the order Malasseziales observed in Olkiluoto fracture zone water were closely related to cultured Malassezia sp. LCP-2008 and uncultured Malassezia from deep sea sediments (Singh et al., 2012). Phylotypes belonging to Malassezia sp. have also been recovered from methane hydrate-bearing deep sea sediments (Lai et al., 2007). These yeast species could potentially be methylotrophic and could play a crucial role in converting methane into more accessible carbon and energy substrates for the use of the microbial community (Lai et al., 2007; Raghukumar et al., 2010). In addition, fungi have been found to be involved in methane release in a coal mine (Beckmann et al., 2011). In the coal mine, weathering of coal, and timber were initiated by fungi and in the lower, oxygen depleted regions fungi were observed to perform incomplete oxidation of coal and wood substrates and release reduced carbon substrates, which can be channeled into methanogenesis.

Chytridiomycota that dominated in DNA-fraction of OLKR44 at 693 m were most similar to the order Rhizophydiales that also have been found in oxygen-deficient marine environments (Raghukumar, 2012). Chytridiomycota are the earliest diverging lineage of fungi and produces zoospores, which indicates adaptation to aquatic environments (Nagano and Nagahama, 2012; Raghukumar, 2012). Chytridiomycota was not detected in RNA fraction. However, statistically significant correlation of fungal taxonomy profiles between total and active communities was found in majority of the fracture zones, which suggests that fungal communities were similar in both DNA and RNA fraction. In three of these samples only weak correlation and in eight of the fracture zones no significance correlation was found, which indicates that total and active communities in these fracture zones were different. In half of samples with no significant correlation insufficient sampling depth of the RNA fraction may have affected the result. In OL-KR6 at $328 \mathrm{~m}$, OLKR9 at $423 \mathrm{~m}$, OL-KR49 at $415 \mathrm{~m}$ and OL-KR25 at $330 \mathrm{~m}$ total and active communities appear to be truly different, suggesting that different species are active in these fracture zones compared to total community. 
The universal distribution of the many fungal species detected also in deep subsurface environments raises the question about possible contamination. It is known that controlling contamination during drilling in hard rock is more difficult than for example sedimentary rock and life dwelling in fracture zones is exposed to drill water during drilling. Origin of the fungi in Olkiluoto fracture zones is unknown and possible runoff from the surface or contamination during drilling cannot be ruled out based on this study. On the other hand, fungi can be authentic members of the microbial community in the different fracture zones. In this study water from the drill hole was purged for a long time after drilling and by using packers only water originating from the specific fracture zone was collected. Hydrogeochemical characteristics of the fracture fluids also indicates that the chemical parameters were stabilized confirming that water from specific fracture zone was collected. Most importantly, active fungi were found from Olkiluoto groundwater and this indicates that fungi have adapted to deep biosphere conditions and are able to maintain cellular activity.

The metabolic activities of fungi in deep terrestrial environment remain still unknown. However, the first fungal metabolic transcriptomics study from sub-seafloor environment confirms the previous suggestions of living fungi and active fungal metabolism in the deep marine biosphere (Orsi et al., $2013 \mathrm{~b})$. The authors showed that $5 \%$ of the obtained transcripts were involved in carbohydrate, amino acid, and lipid metabolism suggesting that fungi have a role in organic carbon cycling in sub-seafloor sediment. Fungal expression of transcripts encoding hydrolases involved in protein, carbohydrate, and lipid degradation suggests that they degrade a variety of organic substrates. Fungal dissimilatory nitrate reductase (nar) transcripts involved in energy production were found, which indicate that fungi are involved in nitrogen cycle, probably

\section{References}

Altschul, S. F., Gish, W., Miller, W., Myers, E. W., and Lipman, D. J. (1990). Basic local alignment search tool. J. Mol. Biol. 215, 403-410. doi: 10.1016/S00222836(05)80360-2

Bazzicalupo, A. L., Bálint, M., and Schmitt, I. (2013). Comparison of ITS1 and ITS2 rDNA in 454 sequencing of hyperdiverse fungal communities. Fungal Ecol. 6, 102-109. doi: 10.1016/j.funeco.2012.09.003

Beckmann, S., Krüger, M., Engelen, B., Gorbushina, A. A., and Cypionka, H. (2011). Role of bacteria, archaea and fungi involved in methane release in abandoned coal mines. Geomicrobiol. J. 28, 347-358. doi: 10.1080/01490451.2010.503258

Blazewicz, S. J., Barnard, R. L., Daly, R. A., and Firestone, M. K. (2013). Evaluating rRNA as an indicator of microbial activity in environmental communities: limitations and uses. ISME J. 7, 2061-2068. doi: 10.1038/ismej. 2013.102

Bomberg, M., Nyyssönen, M., and Itävaara, M. (2012). Characterization of Olkiluoto Bacterial and Archaeal Communities by 454 Pyrosequencing. Working Report 2011-31. Olkiluoto, Posiva.

Bomberg, M., Nyyssönen, M., Pitkänen, P., Lehtinen, A., and Itävaara, M. (2015). Active microbial communities inhabit sulphate-methane interphase in deep bedrock fracture fluids in Olkiluoto, Finland. BMRI 979530.

Buée, M., Reich, M., Murat, C., Morin, E., Nilsson, R. H., Uroz, S., et al. (2009). 454 Pyrosequencing analyses of forest soils reveal an unexpectedly reducing nitrate and nitrite resulting from nitrate reduction performed by bacteria.

In our study surprisingly high diversity of active fungi were detected for the first time in deep groundwater of crystalline rock fractures. Unlike bacterial 16S rRNA gene, the RNA fraction of fungal ITS is only present in the cell when the genomic copy is being actively transcribed and thus is a true evidence that fungi are active in the deep fracture waters (Blazewicz et al., 2013). The most interesting question now is what are these fungi doing in the deep fracture zones in Olkiluoto and in deep terrestrial environment in general and what is their role in the whole microbial community? Metatranscriptomic studies could be the answer and next step in understanding the functionality of the fungal communities in deep subterranean environments. Interesting was that the amount of organic carbon did not correlate with fungal diversity and activity in deep fracture zones suggesting that fungi may have some other functions in deep subterranean environments than degradation of organic materials.

\section{Acknowledgments}

The research project was funded by Posiva Oy and Finnish Research Programme on Nuclear Waste Management (KYT) 2011-2014. Tiina Lamminmäki and Petteri Pitkänen from Posiva Oy are thanked for access to the samples, sample metadata, and fruitful discussions. Mirva Pyrhönen is acknowledged for skillful technical assistance in the laboratory.

\section{Supplementary Material}

The Supplementary Material for this article can be found online at: http://journal.frontiersin.org/article/10.3389/fmicb. 2015.00573/abstract

high fungal diversity. New Phytol. 184, 449-456. doi: 10.1111/j.1469-8137.2009. 03003.x

Caporaso, J. G., Kuczynski, J., Stombaugh, J., Bittinger, K., Bushman, F. D., Costello, E. K., et al (2010). QIIME allows analysis of highthroughput community sequencing data. Nat. Methods 7, 335-336. doi: 10.1038/nmeth.f.303

Cathrine, S. J., and Raghukumar, C. (2009). Anaerobic denitrification in fungi from the coastal marine sediments off Goa, India. Mycol. Res. 113, 100-109. doi: 10.1016/j.mycres.2008.08.009

Chao, A. (1984). Non-parametric estimation of the number of classes in a population. Scandinavian J. Stat. 11, 265-270.

Damare, S., and Raghukumar, C. (2008). Fungi and macroaggregation in deep-sea sediments. Microb. Ecol. 56, 168-177. doi: 10.1007/s00248-0079334-y

Damare, S., Raghukumar, C., and Raghukumar, S. (2006). Fungi in deep-sea sediments of the Central Indian Basin. Deep Sea Res. P. I 53, 14, e27. doi: 10.1016/j.dsr.2005.09.005

Damare, S. R., Nagarajan, M., and Raghukumar, C. (2008). Spore germination of fungi belonging to Aspergillus species under deep sea conditions. Deep Sea Res. P. I 55, 670-678. doi: 10.1016/j.dsr.2008. 02.004

Edgar, R., C. (2010). Search and clustering orders of magnitude faster than BLAST. Bioinformatics 26, 2460-2461. doi: 10.1093/bioinformatics/ btq461 
Edwards, U., Rogall, T., Blöcker, H., Emde, M., and Böttger, E. C. (1989). Isolation and direct complete nucleotide determination of entire genes. Characterization of a gene coding for 16 S ribosomal RNA. Nuc. Aci. Res. 17, 7843-7853. doi: $10.1093 / \mathrm{nar} / 17.19 .7843$

Ekendahl, S., O'Neill, A. H., Thomsson, E., and Pedersen, K. (2003). Characterisation of yeasts isolated from deep igneous rock aquifers of the Fennoscandian Shield. Microb. Ecol. 46, 416-428. doi: 10.1007/s00248-0032008-5

Fournier, D., Lemieux, R., and Couillard, D. (1998). Essential interactions between Thiobacillus ferrooxidans and heterotrophic microorganisms during a wastewater sludge bioleaching process. Env. Pol. 101, 303-309. doi: 10.1016/S0269-7491(98)00035-9

Fredrickson, J. K., and Onstott, T. C. (1996). Microbes deep inside the earth. Sci. Am. 8, 42-47. doi: 10.1038/scientificamerican1096-68

Gadd, G. M. (2006). Fungi in Biochemical Cycles. New York, NY: Cambridge University Press.

Gardes, M., and Bruns, T. D. (1993). ITS primers with enhanced specificity for basidiomycetes - application to the identification of mycorrhizae and rusts. Mol. Ecol. 2, 113-118. doi: 10.1111/j.1365-294X.1993.tb00005.x

Hammer, Ø., Harper, D. A. T., and Ryan, P. D. (2001). PAST: paleontological statistics software package for education and data analysis. Palaeontol. Elect. $4: 1$.

Jebaraj, C. S., Raghukumar, C., Behnke, A., and Stoeck, T. (2010). Fungal diversity in oxygen-depleted regions of the Arabian Sea revealed by targeted environmental sequencing combined with cultivation. FEMS Microbiol. Ecol. 71, 399-412. doi: 10.1111/j.1574-6941.2009.00804.x

Kõljalg, U., Nilsson, R. H., Abarenkov, K., Tedersoo, L., Taylor, A. F. S., Bahram, M., et al. (2013). Towards a unified paradigm for sequence-based identification of fungi. Mol. Ecol. 22, 5271-5277. doi: 10.1111/mec.12481

Kurakov, A. V., Lavrent'Ev, R. B., Nechitailo, T. Y., Golyshin, P. N., and Zvyagintsev, D. G. (2008). Diversity of facultatively anaerobic microscopic mycelial fungi in soils. Mikrobiologiia 77, 90-98. doi: 10.1134/S002626170801013X

Lai, X., Cao, L., Tan, H., Fang, S., Huang, Y., and Zhou, S. (2007). Fungal communities from methane hydrate-bearing deep sea marine sediments in South China Sea. ISME J. 1, 756-762. doi: 10.1038/ismej.2007.51

Lindahl, B. D., Nilsson, R. H., Tedersoo, L., Abarenkov, K., Carlsen, T., Kjøller, R., et al. (2013). Fungal community analysis by high-throughput sequencing of amplified markers-a user's guide. New Phyt. 199, 288-299. doi: 10.1111/nph.12243

Ludvigsen, L., Albrechtsen, H. J., Ringelberg, D. B., Ekelund, F., and Christensen, T. H. (1999). Distribution and composition of microbial populations in landfill leachate contaminated aquifer (Grindsted, Denmark). Microb. Ecol. 37, 197-207. doi: 10.1007/s002489900143

Madsen, E. L., and Ghiorse, W. C. (1993). "Groundwater microbiology: subsurface ecosystem processes," in Aquatic Microbiology, ed T. E. Ford (London: Blackwell Scientific Publications), 167-213.

Manter, D. K., and Vivanco, J. M. (2007). Use of the ITS primers, ITS1F and ITS4, to characterize fungal abundance and diversity in mixed-template samples by qPCR and length heterogeneity analysis. J. Microbiol. Meth. 71, 7-14. doi: 10.1016/j.mimet.2007.06.016

Murrell, P. (2005). R Graphics. WIREs Comp Stat. 1, 216-220. doi: 10.1002/wics.22

Muyzer, G., de Wall, E., and Uitterlinden, A. (1993). Profiling of complex microbial populations by denaturing gradient gel electrophoresis analysis of polymerase chain reaction-amplified genes coding 16S rRNA. Appl. Environ. Microbiol. 59, 695-700.

Nagano, Y., and Nagahama, T. (2012). Fungal diversity in deep sea extreme environments. Fung. Egol. 5, 463-471. doi: 10.1016/j.funeco.2012.01.004

Nagano, Y., Nagahama, T., Hatada, Y., Nunoura, T., Takami, H., Miyazaki, J., et al. (2010). Fungal diversity in deep sea sediments-the presence of novel fungal groups. Fung. Ecol. 3, 316-325. doi: 10.1016/j.funeco.2010.01.002

Nyyssönen, M., Bomberg, M., Kapanen, A., Nousiainen, A., Pitkänen, P., and Itävaara, M. (2012). Methanogenic and sulphate-reducing microbial communities in deep groundwater of crystalline rock fractures in Olkiluoto, Finland. Geomicrobiol. J. 29, 863-878. doi: 10.1080/01490451.2011. 635759

Orsi, W., Biddle, J. F., and Edgcomb, V. (2013b). Deep sequencing of subseafloor eukaryotic rRNA reveals active fungi across marine subsurface provinces. PLOS ONE 8:e56335. doi: 10.1371/journal.pone.00 56335

Orsi, W. D., Edgcomb, V. P., Christman, G. D., and Biddle, J. F. (2013a). Gene expresssion in the deep biosphere. Nature 499, 205-208. doi: 10.1038 /nature 12230

Palumbo, A. V., Zhang, C., Liu, S., Scarborough, S. P., Pfiffner, S. M., and Phelps, T. J. (1996). "Influence of media on measurement of bacterial populations in the subsurface," in Seventeenth Symposium on Biotechnology for Fuels and Chemicals, eds C. E. Wyman and B. H. Davison (Totowa, NJ: Humana Press), 905-914.

Pedersen, K. (1987). Preliminary Investigations of Deep Groundwater Microbiology in Swedish Granitic Rock. SKB Technical report 88-01. Stockholm: Swedish Nuclear Fuel and Waste Management Co.

Pedersen, K., Arlinger, J., Ekendahl, S., and Hallbeck, L. (1996). 16S rRNA gene diversity of attached and unattached bacteria in boreholes along the access tunnel to the Äspö Hard Rock Laboratory. FEMS Microbiol. Ecol. 19, 249-262. doi: 10.1016/0168-6496(96)00017-7

Pitkänen, P., Partamies, S., and Luukkonen, A. (2004). Hydrogeochemical Interpretation of Baseline Groundwater Conditions at the Olkiluoto Site. Olkiluoto; Posiva.

Posiva. (2013). Olkiluoto Site Description 2011. Eurajoki: POSIVA 2011-02.

Raghukumar, C. (2012). Biology of Marine Fungi. Heidelberg: Springer.

Raghukumar, C., Damare, S. R., and Singh, P. (2010). A review on deep-sea fungi: occurrence, diversity and adaptations. Botan. Mar. 53, 479-492. doi: 10.1515/bot.2010.076

Raghukumar, C., and Raghukumar, S. (1998). Barotolerance of fungi isolated from deep sea sediments of the Indian Ocean. Aquat. Microb. Ecol. 15, 153-163. doi: 10.3354/ame015153

R Development Core Team. (2008). R: A Language and Environment for Statistical Computing. Vienna: R Foundation for statistical Computing. Available online at: http://www.R-project.org

Reitner, J., Schumann, G., and Pedersen, K. (2006). "Fungi in subterranean environments," in The Fungi in Biogeochemical Cycles, ed G. M. Gadd (Cambridge: Cambridge University Press), 377-403.

Salavirta, H., Bomberg, M., Nyyssönen, M., Miettinen, H., Sohlberg, E., Vikman, M., et al. (in press). Archaea have thrived and diversified in deep subsurface Fennoscandian aquifers. Front. Microbiol.

Schloss, P. D., Westcott, S. L., Ryabin, T., Hall, J. R., Hartmann, M., Hollister, E. B., et al. (2009). Introducing mothur: open- source, platform-independent, community-supported software for describing and comparing microbial communities. Appl. Env. Microbiol. 75, 7537-7541. doi: 10.1128/AEM. 01541-09

Shannon, C. E. (1948). A mathematical theory of communication. Bell Syst. Tech. J. 27, 379-423, 623-656. doi: 10.1002/j.1538-7305.1948.tb 01338.x

Sinclair, J. L., and Ghiorse, W. C. (1989). Distribution of aerobic bacteria, protozoa, algae, and fungi in deep subsurface sediments. Geomicrobiol. J. 7, 15-31. doi: $10.1080 / 01490458909377847$

Singh, P., Raghukumar, C., Verma, P., and Shouche, Y. (2012). Assessment of fungal diversity in deep sea sediments by multiple primer approach. World J. Microbiol. Biotechnol. 28, 659-667. doi: 10.1007/s11274-01 1-0859-3

Sterflinger, K. (2010). Fungi as geologic agents. Geomicrobiol. J. 17, 97-124. doi: 10.1080/01490450050023791

Takishita, K., Tsuchiya, M., Reimer, J. D., and Maruyama, T. (2006). Molecular evidence demonstrating the basidiomycetous fungus Cryptococcus curvatus is the dominant microbial eukaryote in sediment at the Kuroshima Knoll methane seep. Extremophiles 10, 165-169. doi: 10.1007/s00792-0050495-7

Takishita, K., Yubuki, N., Kakizoe, N., Inagaki, Y., and Maruyama, T. (2007). Diversity of microbial eukaryotes in sediment at a deep sea methane cold seep: surveys of ribosomal DNA libraries from raw sediment samples and two enrichment cultures. Extremophiles 11, 563-576. doi: 10.1007/s00792-0070068-Z

Wainwright, M., and Grayston, S. J. (1989). “Accumulation and oxidation of metal sulphides by fungi," in Metal-Microbe Interactions, ed K. Sterflinger (Oxford: IRL press), 119-131. 
White, T. J., Bruns, T., Lee, S. J. W. T., and Taylor, J. W. (1990). Amplification and direct sequencing of fungal ribosomal RNA genes for phylogenetics. PCR Protoc. 18, 315-322. doi: 10.1016/b978-0-12-372180-8.50042-1

Wickham, H. (2007). Reshaping Data with the reshape Package. J. Stat. Soft. 21, $1-20$.

Wickham, H. (2009). Ggplot2: Elegant Graphics for Data Analysis. New York, NY; Springer. doi: 10.1007/978-0-387-98141-3-2

Zhang, N., Castlebury, L. A., Miller, A. N., Huhndorf, S. M., Schoch, C. L., Seifert, K. A., et al. (2006). An overview of the systematics of the Sordariomycetes based on a four- gene phylogeny. Mycologia 98, 1076-1087. doi: 10.3852 /mycologia.98.6.1076
Conflict of Interest Statement: Posiva Oy funded this research. The authors declare that the research was conducted in the absence of any commercial or financial relationships that could be construed as a potential conflict of interest.

Copyright (๑) 2015 Sohlberg, Bomberg, Miettinen, Nyyssönen, Salavirta, Vikman and Itävaara. This is an open-access article distributed under the terms of the Creative Commons Attribution License (CC BY). The use, distribution or reproduction in other forums is permitted, provided the original author(s) or licensor are credited and that the original publication in this journal is cited, in accordance with accepted academic practice. No use, distribution or reproduction is permitted which does not comply with these terms. 